Revista de la red interuniversitaria de estudios sobre las literaturas rioplatenses contemporáneas en Francia

$14 \mid 2016$

Levrero

\title{
Enciclopedia de la Belleza
}

\section{Tía Encarnación}

URL: http://journals.openedition.org/lirico/2307

DOI: $10.4000 /$ lirico. 2307

ISSN: 2262-8339

Editor

Réseau interuniversitaire d'étude des littératures contemporaines du Río de la Plata

\section{Referencia electrónica}

Tía Encarnación, «Enciclopedia de la Belleza », Cuadernos LIRICO [En línea], 14 | 2016, Puesto en línea el 07 junio 2016, consultado el 21 abril 2019. URL : http://journals.openedition.org/lirico/2307 ; DOI : 10.4000/lirico.2307

Este documento fue generado automáticamente el 21 abril 2019.

\section{(c) (1) $\Theta \Theta$}

Cuadernos LIRICO está distribuido bajo una Licencia Creative Commons Atribución-NoComercialSinDerivar 4.0 Internacional. 


\section{Enciclopedia de la Belleza}

\section{Tía Encarnación}

\section{Fascículo 1}

\section{El cuidado de la piel}

¿Cómo hacer que nuestra piel luzca joven y hermosa?

3 En primer lugar, debemos identificar cuál es nuestro tipo de piel, y luego atender los consejos prácticos que damos para cada uno de ellos.

4 1.- Piel grasa- Se la reconoce fácilmente por el asco que despierta en la gente. La cara se ve cubierta por multitud de gruesas gotas pegajosas que a veces se empastan entre sí formando una superficie continua, resbalosa y adherente, la que se va acumulando por acción de la gravedad en la parte inferior del rostro y de las orejas, y desde allí gotea lentamente bajo la forma de un líquido gelatinoso. Si al pasarse los dedos por la cara, éstos le quedan pringosos y grasientos, como untados de manteca o de algo peor, es porque usted tiene piel grasa. También se reconoce este tipo de piel por su propensión a que se le adhieran todo tipo de cosas -desde el polvillo que flota en el aire, el hollín y la tierra, hasta moscas, pedazos de papel y hojas secas de los árboles.

5 La causa de la piel grasa es el trabajo excesivo de las glándulas sebáceas (ver figura 1-A), que responden a estímulos que el cerebro transmite mediante el nervio sebáceo. Se ha intentado resolver este problema mediante la cirugía, extirpando gran parte de estos nervios, pero la operación es delicada, costosa y larga -ya que hay unas 15 glándulas por centímetro cuadrado de piel. En casos extremos se ha optado por extirpar directamente el cerebro, causa principal del problema : sin embargo, la mayoría de las mujeres prefieren soluciones cosmetológicas.

6 Cuidados y tratamientos.- Los factores climáticos y agentes naturales que más la perjudican son el calor, el frío, las lluvias, tormentas, vendavales, temporales, tifones y maremotos, así como el frotamiento excesivo con hojas de ortiga macho.

7 Aplicarse todas las noches unos trapos embebidos en disán u otro disolvente químico, y por la mañana una buena crema nutritiva, si es que le quedó algo de cara para nutrir. 


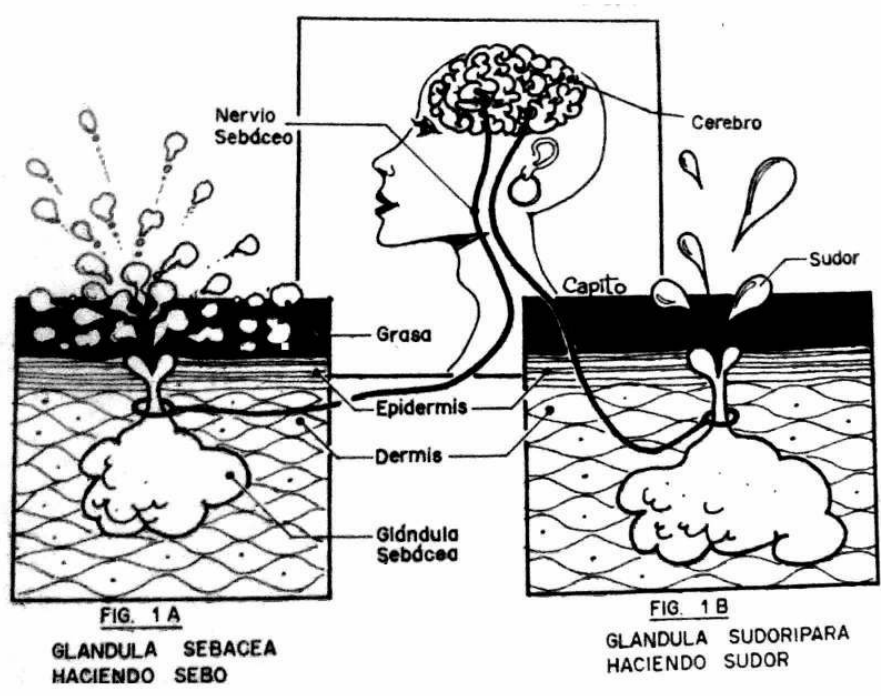

8 2.- Piel seca.- Se la reconoce por ser muy blanca y frágil y porque se irrita y arruga fácilmente. Al tacto aparece rasposa, y los dedos no resbalan sobre ella con facilidad, como en esas hermosas pieles grasientas, sino que se van trancando y enganchando y se mueven dando saltitos. Si bien este tipo de piel tiene la ventaja de que la tierra no se le pega, en cambio se le acumula entre las arrugas, grietas y asperezas, permitiendo la formación de como pequeños cultivos agrícolas: a menudo crecen en ella pequeñas formaciones de musgo o matas de yuyos silvestres -las que de lejos se confunden con barba, bigote $\mathrm{u}$ otras clases de pelos que crecen en la cara.

La causa de la piel seca es, naturalmente, el trabajo desganado o nulo de las glándulas sebáceas, o la total y absoluta carencia de las mismas.

Cuidados y tratamientos.- Sus principales enemigos son : la humedad y las hormigas.

De noche, antes de acostarse, rastrillar bien, y después escarbar con mucha paciencia mediante un palillo de dientes grieta por grieta para sacar la tierra. De mañana al levantarse aplíquese una capa de arena fina y pórlan, y por encima el maquillaje que prefiera.

3.- Piel deshidratada.- Puede ser tanto seca como grasa : aquí el problema reside en las glándulas sudoríparas (ver fig. 1-B), con un esquema de funcionamiento similar al de las sebáceas. Esta piel se reconoce por su aspecto reseco, áspero al tacto como el papel de lija, por la sed que produce en quien la mira, por las cuarteaduras y porque al tomar una parte de la mejilla entre dos dedos (de una mano) hace unos ruiditos como de quién pisa cáscaras de huevo, y después se cae en pedazos.

Cuidados y tratamientos.- Debe cuidarse de los vientos fuertes y arrachados, que además se le pueden llevar la peluca y los dientes postizos -como le pasó a una cuñada mía cuando iba a una fiesta y tuvo entonces que volverse a la casa, y nunca más volvió a salir. En invierno debe evitarse pasar bruscamente de un ambiente calefaccionado al exterior, y viceversa. Cuando está de visita en una casa calefaccionada, vaya arrimándose de a poco a la puerta de calle; como quien no quiere la cosa, y después de abrir la puerta déjela un rato así; despídase largamente de los dueños de casa, prolongando los besos y los apretones de mano y recordando siempre una nueva anécdota, para permitir que su piel se vaya adaptando al cambio. Lo mismo antes de entrar : quédese un buen rato con un pie 
adentro y el otro afuera de la casa, como atacada por una súbita timidez, y repita varias veces : "Realmente no sé si es procedente visitarlos a esta hora ; tal vez están ocupados".

14 4.- Piel hiperhidratada.- Son estas pieles sudadas, que siempre chorrean agua, como los jugadores de fútbol hacia el final del segundo tiempo pero en este caso sin jugar a nada. La culpa también la tienen en este caso las glándulas sudoríparas.

15 Cuidados y tratamientos.- A este tipo de piel la favorece el viento, por su acción evaporadora del sudor, y todos los demás agentes la perjudican. Cuando no hay viento, trate de ponerse siempre cerca de un ventilador, o consígase alguien que le sople. Duerma con la cara envuelta entre hojas de papel secante y de mañana aplíquese cualquier cosa, que igual no hay nada que sirva.

5.- Piel normal.- Es el peor de los tipos de piel ; bajo su aspecto lozano y juvenil, oculta las porquerías más grandes que uno pueda imaginarse y que nuestra pluma se resiste a describir.

Y preferimos no seguir hablando de este delicado tema, corriendo sobre el mismo un discreto velo de silencio.

18 6.- Piel mixta.- Es un tipo de piel que a los males de la piel grasa le suma los de la piel seca y la deshidratada, así como los de la hiperhidratada y (¡Dios míos!) la normal ; pero no todo junto y superpuesto sino por pequeños sectores y en forma arbitraria. Tiene partes ásperas y partes engrasadas, partes donde crece una espesa vegetación entre las grietas llenas de tierra, otras que largan chijetes de sudor y otras de apariencia (jay!) normal.

Cuidados y tratamientos.- Como puede imaginarse, todos los factores climáticos y todos los agentes, naturales o no, le son profundamente hostiles; porque lo que le va bien a un pedazos de la cara, le va horrible a los otros. Ni siquiera le ayuda quedarse en su casa. Compre cuanta crema existe y aplíquese un poco en cada sector, o bien mézclelas todas en una sola pasta y pásela por toda la cara, o mejor aún no compre nada, no se ponga nada, deje todo como está, olvídese de todo. 